\title{
Assessment of post-laparotomy pain in laboratory mice by telemetric recording of heart rate and heart rate variability Margarete Arras*1, Andreas Rettich ${ }^{1}$, Paolo Cinelli², Hans P Kasermann ${ }^{2}$ and Kurt Burki²
}

\author{
Address: ${ }^{1}$ University of Zurich, Institute of Laboratory Animal Science, Sternwartstr. 6, CH - 8091 Zurich, Switzerland and ${ }^{2}$ University of Zurich, \\ Institute of Laboratory Animal Science, Winterthurerstr. 190, CH - 8057 Zurich, Switzerland \\ Email: Margarete Arras* - arras@ltk.uzh.ch; Andreas Rettich - andreas.rettich@ltk.uzh.ch; Paolo Cinelli - paolo.cinelli@ltk.uzh.ch; \\ Hans P Kasermann - kaserman@ltk.uzh.ch; Kurt Burki - kbuerki@ltk.uzh.ch \\ * Corresponding author
}

Published: 2 August 2007

BMC Veterinary Research 2007, 3:16 doi:10.1186/1746-6/48-3-16

This article is available from: http://www.biomedcentral.com/l746-6/48/3/16

(c) 2007 Arras et al; licensee BioMed Central Ltd.

This is an Open Access article distributed under the terms of the Creative Commons Attribution License (http://creativecommons.org/licenses/by/2.0), which permits unrestricted use, distribution, and reproduction in any medium, provided the original work is properly cited.
Received: I4 February 2007

Accepted: 2 August 2007

\begin{abstract}
Background: Pain of mild to moderate grade is difficult to detect in laboratory mice because mice are prey animals that attempt to elude predators or man by hiding signs of weakness, injury or pain. In this study, we investigated the use of telemetry to identify indicators of mild-to-moderate postlaparotomy pain.

Results: Adult mice were subjected to laparotomy, either combined with pain treatment (carprofen or flunixin, $5 \mathrm{mg} / \mathrm{kg} \mathrm{s} / \mathrm{c}$ bid, for I day) or without pain relief. Controls received anesthesia and analgesics or vehicle only. Telemetrically measured locomotor activity was undisturbed in all animals, thus confirming that any pain experienced was of the intended mild level. No symptoms of pain were registered in any of the groups by scoring the animals' outer appearance or spontaneous and provoked behavior. In contrast, the group receiving no analgesic treatment after laparotomy demonstrated significant changes in telemetry electrocardiogram recordings: increased heart rate and decreased heart rate variability parameters pointed to sympathetic activation and pain lasting for 24 hours. In addition, core body temperature was elevated. Body weight and food intake were reduced for 3 and 2 days, respectively. Moreover, unstructured cage territory and destroyed nests appeared for $\mathrm{I}-2$ days in an increased number of animals in this group only. In controls these parameters were not affected.
\end{abstract}

Conclusion: In conclusion, real-time telemetric recordings of heart rate and heart rate variability were indicative of mild-to-moderate post-laparotomy pain and could define its duration in our mouse model. This level of pain cannot easily be detected by direct observation.

\section{Background}

Laboratory mice are currently the most widely used animal species in biomedical research. Their popularity is due to the availability of a wealth of spontaneous or experimentally induced mutants, allowing the in vivo functions of single genes to be studied. Therefore, mice provide powerful models with which to explore the regulation of cellular and physiologic processes. Mice are also increasingly used in complex investigations requiring additional surgical intervention. Doubtless, post-opera- 
tive pain relief following surgical procedures such as laparotomy would seem to be necessary, but is often omitted as documented in a recent survey [1]. A reason given for withholding analgesics from laboratory rodents is that no signs of pain were observed and therefore analgesics were considered to be unnecessary.

Indeed, after minor surgery, signs of pain are barely observable in mice. From post-operative monitoring, which usually consists of visual inspection of the animal's appearance, posture, and spontaneous behavior, only the generalized, well-known symptoms of considerable or severe pain and suffering can be detected, e.g., piloerection, unkempt coat/rough hair, hunched posture, apathy, aggression, and self-mutilation [2-5].

An explanation for the phenomenon that pain of moderate grades is not visible in mice is that prey animals live in constant fear of falling victim to their enemies, therefore they tend to show as few signs of disease, suffering or weakness as possible. This instinctive strategy is intended to avoid attracting the attention of predators, including man. Therefore, during animal experiments, or even when a person is simply present in the room, the mouse will hide signs of pain [5-7], making monitoring of low-tomoderate pain difficult.

This problem can be circumvented by using telemetry, which allows monitoring without the presence of the investigator in the vicinity of the animal. Using commercially available radiotelemetric transmitters, physiological and behavioral parameters can be recorded in real-time over several days after surgery in rodents [8]. Such recordings provide information about the time course of disturbances in these parameters that cannot be obtained with such accuracy from retrospective measurements such as loss of body weight and reduction in food intake.

Telemetry in mice to measure physiological parameters such as heart rate (HR), core body temperature (BT), or blood pressure has been established. These latter parameters have been recommended as additional indices to appearance and behavior in determining pain scales for animals $[3,6,7,9]$. Since these measures are not specific to pain per se, their relevance in the assessment of pain must be worked out with specific types of pain excluding external influences. In this study, we aimed to identify telemetrically measurable indicators of mild-to-moderate postlaparotomy pain in mice. In addition, two regimens for pain relief were assessed.

\section{Results}

\section{Animals and housing conditions}

Twenty-six male HsdHan:NMRI mice were obtained from a commercial supplier (Harlan, Horst, The Netherlands).
The mice were free of the viral, bacterial, and parasitic pathogens listed in the recommendations of the Federation of European Laboratory Animal Science Association [10]. Their health status was monitored by a sentinel program throughout the experiments. Animals were obtained at the age of 4 weeks. Telemetric transmitters were implanted after an adaptation period of 4 weeks, i.e., at 8 weeks of age. The experiments were conducted when the mice were aged 4-6 months, with body weights ranging from 40 to $54 \mathrm{~g}$. In general, each male was housed together with an adult, ovarectomized female companion mouse, except that each animal was housed individually for two weeks after transmitter implantation and during the experiments. Housing in compatible pairs with an infertile female allowed normal social interaction of the experimental mature males while production of unwanted progeny was prevented. During the recovery phase from surgical interventions (transmitter implantation, vasectomy), the female companion was suspected to disturb healing processes and influence measurements (e.g. nest building). To exclude the impact of the companions' actions on recovery and read out, the experimental animals were housed individually during transient time periods.

Animals were kept in type 3 filter-top clear-transparent plastic cages $(425 \mathrm{~mm} \times 266 \mathrm{~mm} \times 150 \mathrm{~mm}$, floor area $\left.820 \mathrm{~cm}^{2}\right)$ with autoclaved dust-free sawdust bedding $(80-$ $90 \mathrm{~g} /$ cage) and autoclaved hay (18-20 g/cage) as nesting material. They were fed a pelleted and extruded mouse diet (Kliba No. 3431, Provimi Kliba, Kaiseraugst, Switzerland) ad libitum and had unrestricted access to sterilized drinking water. The light/dark cycle in the room consisted of 12/12 h (07:00-19:00) with artificial light (40 Lux in the cage). The temperature was $21 \pm 1{ }^{\circ} \mathrm{C}$, with a relative humidity of $50 \pm 5 \%$, and with 15 complete changes of filtered air per hour (HEPA H 14 filter); the air pressure was controlled at $50 \mathrm{~Pa}$. The animal room was insulated to prevent electronic noise. Disturbances (e.g., visitors or unrelated experimental procedures) were not allowed. To avoid interfering influences, all necessary husbandry and management procedures were completed in the room at least 3 days before starting an experiment.

Housing and experimental protocols were approved by the Cantonal Veterinary Department, Zurich, Switzerland, under license no. $\mathrm{ZH} \mathrm{82/2004}$ and were in accordance with Swiss Animal Protection Law. Housing and experimental procedures were also in accordance with the Guide for the Care and Use of Laboratory Animals (Institute of Laboratory Animal Resources, National Research Council, National Academy of Sciences, 1996). 


\section{Preliminary transmitter implantation}

TA10ETA-F20 transmitters (Data Sciences International, St. Paul, MN, USA), which are able to process heart rate (HR), electrocardiogram (ECG), core body temperature (BT), and locomotor activity (ACT) in freely moving mice, were implanted as previously described [11]. The mice were anesthetized by inhalation of the volatile anesthetic sevoflurane (Sevorane ${ }^{\mathrm{TM}}$, Abbott, Cham, Switzerland) at a concentration of $5-8 \%$ in $100 \%$ oxygen at a flow rate of $200 \mathrm{ml} / \mathrm{min}$. The anesthetic gas was administered with a nose mask. Ketamine (Ketasol-100 ${ }^{\mathrm{TM}}$, Dr. Graub, Bern, Switzerland) was injected subcutaneously as pre-medication at a dosage of $45 \mathrm{mg} / \mathrm{kg}$ body weight as pre-emptive analgesia. The abdomen was opened by mid-line laparotomy and the telemetric transmitter body was implanted under aseptic conditions into the abdominal cavity of the mouse. One telemetry lead was tunneled subcutaneously from the thorax to the neck, where the wired loop electrode was fixed between the muscles located to the right of the trachea. The other wired loop lead was sutured to the xiphoid process with a silk thread. The muscle layers and the skin were then closed with resorbable sutures. Postoperative pain was treated with buprenorphine (Temgesic $^{\mathrm{TM}}$, Reckitt and Colman Products Ltd., Hull, England), at a dose of $0.1 \mathrm{mg} / \mathrm{kg}$ body weight, injected subcutaneously twice per day for 4 days. Animals were monitored daily for 10 days after the surgery for appearance, posture, spontaneous moving behavior, body weight, and food and water consumption. After transmitter implantation, the mice had a period of 8 weeks convalescence until the start of the first experiment.

\section{Experimental design}

Six experiments were performed: unilateral laparotomy either without subsequent analgesic treatment or with carprofen or flunixin treatment. Surgery was omitted in control groups, which received only anesthesia and injections of vehicle, carprofen or flunixin.

Mice were distributed randomly with regard to age and experiment. Each experiment was performed on 2-3 dates to reach a group size of 8 animals. For mice that underwent more than one experiment (26 mice/48 experiments), a break of at least two weeks between experiments was provided.

To avoid any influence of the circadian rhythm, the anesthesia, laparotomy and weighing procedures were conducted between 17:30 and 18:30 h, i.e., at the end of the light phase. All interventions were carried out in the animal room to preclude disturbance by transport and to ensure constant conditions.

\section{Method of establishing baseline values}

To start an experiment, the transmitter-bearing male was separated from its infertile female companion and put in a fresh cage. For three days, the animal was allowed to settle in to the new territory and stabilize in single housing conditions without being disturbed.

Measurements were then started by obtaining the individual's baseline values for three consecutive days before laparotomy.

\section{Anesthesia and laparotomy experiments}

For laparotomy and control experiments, animals were anesthetized for 10-11 minutes with sevoflurane (Sevorane $^{\mathrm{TM}}$, Abbott, Cham, Switzerland) via a nose cone as follows: the animal was taken out of its cage, placed on the cage lid, restrained by the scruff of the neck and transferred onto an autoclaved, heated $\left(39^{\circ} \mathrm{C}\right)$ operating table. There, its nose was placed in a face mask in which sevoflurane $(7 \%)$ in oxygen $(100 \%)$ was delivered (flow rate 200 $\mathrm{ml} / \mathrm{min}$ ) by an inhalation anesthesia device equipped with a vaporizer and a purpose-made gas delivery and scavenging system. After 10-15 seconds, the mouse lost the righting reflex and was turned onto its back, while its nose remained in the cone. Eyes were protected with ointment (Vitamine A, Bausch \& Lomb, Steinhausen, Switzerland) and the lower abdominal region of the body was disinfected with alcohol (80\%). After 5 minutes of anesthesia, the analgesic or vehicle injection was administered subcutaneously in the lateral abdominal region. The vehicle consisted of $2 \mu \mathrm{l}$ phosphate buffered saline (PBS)/ g body weight. Carprofen (Rimadyl ${ }^{\mathrm{TM}}$, Pfizer Inc., NY, USA) and flunixin (Biokema Flunixine ${ }^{\mathrm{TM}}$, Biokema SA, Crissier-Lausanne, Switzerland) were diluted in PBS to be applied at a dosage of $5 \mathrm{mg} / \mathrm{kg}$ body weight at the adequate volume of $2 \mu \mathrm{l} / \mathrm{g}$ body weight. Anesthesia was completed in the control groups without further intervention.

For laparotomy, the left or right inguinal region of the abdomen was opened with a small cut $(<0.5 \mathrm{~cm})$ in the skin and the muscular abdominal wall using sterile surgical instruments. The spermatic duct was ligated twice with a silk thread (6-0, Perma-Hand ${ }^{\mathrm{TM}}$ Seide, Ethicon, Norderstedt, Germany) and cut between the sutures, thus conducting unilateral vasectomy. The muscle layers were closed with resorbable sutures (6-0, Vicryl ${ }^{\mathrm{TM}}$, Ethicon, Norderstedt, Germany) and the skin restored with staples (Precise $^{\mathrm{TM}}, 3 \mathrm{M}$ Health Care, St. Paul, MN, USA). Surgery was completed within 6-7 minutes.

When anesthesia was finished, the mouse was put back in its home cage, where it was able to move and orientate within the following 5-10 minutes. 
All manipulations were completed by $18: 30 \mathrm{~h}$ and the investigator had left the animal room before the night phase began. Twelve hours after the first injection of vehicle or analgesics, a second subcutaneous injection of the same substance and dosage was administered.

Data were collected for three days after laparotomy and anesthesia.

\section{Methods of data acquisition}

Measurements started with the first baseline recordings at 8 weeks after transmitter implantation. Data were collected over 3 days for baseline values and after an experiment.

Telemetric measurements were processed using the Dataquest LabPRO program, version 3.11. The telemetric transmitter was switched on by touching the animal with a magnet; signals were detected by a receiver plate placed underneath the animal's cage.

HR values and ECG curves were recorded for 30 seconds every 5 minutes (sampling frequency $1000 \mathrm{~Hz}$ ). ECG curves were subjected to a time domain analysis of heart rate variability (HRV) as defined $[12,13]$. The interbeat interval (IBI) and the standard deviation of interbeat interval (SDNN) were calculated from each segment measured. ACT was recorded continuously and stored at 5 minute intervals. BT was sampled for 10 seconds every 5 minutes.

Values of body weight, food and water consumption were established by weighing the animal, the food pellets and water bottle daily using a precision balance (PR 2003 Delta Range, Mettler-Toledo AG, Greifensee, Switzerland) especially designed to weigh moving animals.

The weighing procedure normally provokes the mouse to express reactions such as flight or attention, which are particularly apparent after the animal is returned to its cage. Therefore, mice were observed for 20-30 seconds before, during and after weighing to register spontaneous and provoked behavior and movements. These behaviors were scored together with clinical findings on the mouse's body once per day and additionally at 12 hours after laparotomy and anesthesia in order to identify signs of pain or disease. The parameters used for this observation of the animal are defined in the score sheet (Table 1). Each individual animal was scored 0 or 1 .

The appearance of the cage, with a detailed description of its overall territorial structure and the condition of the nest was sketched on paper. This was carried out at 12hour intervals without opening the cage or disturbing the mouse.

Table I: Scoring for examination of the animal and its cage

\begin{tabular}{|c|c|c|}
\hline & Score 0 & Score I \\
\hline \multicolumn{3}{|l|}{ Observation of the animal } \\
\hline Spontaneous behavior & $\begin{array}{l}\text { Sleeping, resting, digging, running, walking, } \\
\text { rearing, climbing, eating, drinking, grooming, } \\
\text { sniffing }\end{array}$ & $\begin{array}{l}\text { Sudden movements, backwards movements, } \\
\text { transient involuntary muscular contraction of } \\
\text { any body part, kicking with hind paws, licking/ } \\
\text { biting the wound }\end{array}$ \\
\hline Posture & Lying, sitting, moving, & Hunched, arched back, crouched \\
\hline Breathing & Undisturbed, regular & Exerted, irregular \\
\hline Coat condition & Clean, smooth, well-groomed & $\begin{array}{l}\text { Ruffled, dirty, unkempt, piloerection, hair loss } \\
\text { (alopecia) }\end{array}$ \\
\hline Eyes & Clear, bright & Discharge \\
\hline Body condition & $\begin{array}{l}\text { Good, unchanged as judged from external } \\
\text { appearance }\end{array}$ & Sunken flanks, swollen areas, ascites \\
\hline Wound & Clean, dry, smooth & $\begin{array}{l}\text { Dirty, bloody, uncleaned, signs of self-injury, } \\
\text { signs of inflammation or necrosis, i.e., unusual } \\
\text { color (e.g., red, pale) or swollen }\end{array}$ \\
\hline Behavior after provocation/weighing & Alert, ready to take flight & $\begin{array}{l}\text { Apathetic, sedated, highly aggressive, increased } \\
\text { vocalization }\end{array}$ \\
\hline Movement after provocation/weighing & No aberration in moving pattern & $\begin{array}{l}\text { Decelerated/slowed, crawling, immobile, } \\
\text { lameness, tiptoe gait }\end{array}$ \\
\hline \multicolumn{3}{|l|}{ Appearance of cage } \\
\hline Condition of nest & A nest clearly identifiable & $\begin{array}{l}\text { Either no nest identifiable or multiple } \\
\text { fragmentary nest-like resting places at different } \\
\text { locations }\end{array}$ \\
\hline Condition of territory & $\begin{array}{l}\text { Cage area clearly structured, i.e., obvious areas } \\
\text { for defecation and sleeping }\end{array}$ & $\begin{array}{l}\text { Areas of defecation and sleeping } \\
\text { indistinguishable, feces either adhering to } \\
\text { nesting materials or not visible }\end{array}$ \\
\hline
\end{tabular}




\section{Methods of data analysis}

Baseline telemetric recordings were recorded for 3 days to assess whether the individual's data were stable from day to day. The means of the dark and light phase from the final day of baseline recording was used as each individual's baseline data. For each day after laparotomy/ anesthesia, the mean of the dark and light phase was compared with the individual's baseline data, resulting in delta values. For HR, 3-hour means were additionally calculated by the same method (comparison with the corresponding baseline daytime data for each individual) from the first day after an experiment to allow construction of more detailed time courses of changes.

Baseline data for body weight, food and water consumption were summarized as the average of three days and compared with each day after laparotomy/anesthesia for each individual. Results are presented as the percentage deviation (delta).

Telemetric and weighing results are presented as mean \pm standard error of mean (SEM).

Statistical analysis of telemetric data, as well as daily body weights and food and water consumption, was carried out using the program SPSS for Windows, version 13.0. The values obtained after anesthesia/laparotomy were compared with the individual's baseline values using twotailed paired Student's $t$-test, with Bonferroni correction for multiple comparisons. Since three comparisons were made for 3-hour means of HR and for body weight, and food and water consumption, the alpha level was set at $0.05 / 3=0.0166$ resulting in significance if the value of $P$ was $\leq 0.016$. Six comparisons were performed for the means of the dark and light phase, therefore the alpha level was set at $0.05 / 6=0.0083$, with significance if the value of $P$ was $\leq 0.008$.

The sketches of the appearance of the cage were analyzed by a blinded investigator. The overall structure of the cage was assessed by the visibility of fixed areas for sleeping and/or defecation vs. lack of such structuring. The condition of the nest was assessed with focus on whether a nest was clearly identifiable or not. The sketches were scored as described in Table 1 and scores were finally condensed as the number of animals arranging their territory and nest in a specific manner (Table 2).

\section{Results of baseline measurements}

Baseline recordings of $\mathrm{HR}, \mathrm{IBI}, \mathrm{SDNN}, \mathrm{ACT}$ and BT showed similar levels from day to day in each individual. Baseline curves of body weight, food and water consumption exhibited a few outliers, mainly in water bottle weighing. Analysis of cage sketches showed that all animals had built a proper nest and had established clear structuring of their habitat during the 3-day stabilization period. In all cases, the condition of the nest and the overall territorial structure was maintained during the baseline phase.

\section{Deviations of telemetrically measured parameters}

Figure 1 illustrates the mean changes in HR measured in the 3-hour period immediately after the animals were returned to their home cage after anaesthesia/laparotomy, and in two 3-hour periods at the end of the first day, i.e., 18-21 $\mathrm{h}$ and 21-24 $\mathrm{h}$; during all three time intervals, the highest values were recorded in mice that had undergone laparotomy without subsequent pain treatment $(P=$ 0.001 at $1-3 \mathrm{~h} ; P=0.008$ at $18-21 \mathrm{~h} ; P=0.060$ at $21-24$ $\mathrm{h})$. During the first 3 hours after recovery from anesthesia, the groups treated with carprofen $(P=0.002$ at $1-3 \mathrm{~h})$ or flunixin $(P=0.003$ at $1-3 \mathrm{~h})$ showed increased values, but by the end of the first day HR was normalized in the treated groups, whereas values remained elevated in the group in which analgesics were withheld after laparotomy.

Plotting the results as 12-hour means over the 3 days following the experimental procedure (Figure 2) revealed that HR was significantly increased in the laparotomy group without pain treatment during the first 24 hours $(P$ $=0.001$ at $0-12 \mathrm{~h} ; P=0.000$ at $12-24 \mathrm{~h}$ ) and again in the

Table 2: Number of cages out of 8 estimated as Score $I$ at the time points indicated.

\begin{tabular}{|c|c|c|c|c|c|c|c|c|c|c|c|c|}
\hline & \multicolumn{2}{|c|}{$\begin{array}{l}\text { Laparotomy without } \\
\text { pain treatment }\end{array}$} & \multicolumn{2}{|c|}{$\begin{array}{l}\text { Laparotomy with } \\
\text { carprofen }\end{array}$} & \multicolumn{2}{|c|}{$\begin{array}{l}\text { Laparotomy with } \\
\text { flunixin }\end{array}$} & \multicolumn{2}{|c|}{$\begin{array}{l}\text { control: anesthesia } \\
\text { with vehicle }\end{array}$} & \multicolumn{2}{|c|}{$\begin{array}{l}\text { control: anesthesia } \\
\text { with carprofen }\end{array}$} & \multicolumn{2}{|c|}{$\begin{array}{l}\text { control: anesthesia } \\
\text { with flunixin }\end{array}$} \\
\hline & nest & territory & nest & territory & nest & territory & nest & territory & nest & territory & nest & territory \\
\hline Baseline & 0 & 0 & 0 & 0 & 0 & 0 & 0 & 0 & 0 & 0 & 0 & 0 \\
\hline $12 \mathrm{~h}$ & 5 & 6 & 0 & I & 2 & 4 & I & I & 0 & 3 & 2 & 4 \\
\hline $24 \mathrm{~h}$ & 6 & 6 & I & 0 & 1 & 2 & 0 & 0 & 0 & 0 & 0 & 2 \\
\hline $36 \mathrm{~h}$ & 3 & 5 & 0 & 0 & I & 0 & 0 & 0 & 0 & 0 & 0 & 0 \\
\hline $48 \mathrm{~h}$ & 3 & 5 & 0 & 0 & 2 & 0 & 0 & I & 0 & 0 & 0 & 0 \\
\hline $60 \mathrm{~h}$ & 1 & 2 & I & 0 & 0 & 0 & 0 & 0 & 0 & 0 & 0 & 0 \\
\hline $72 \mathrm{~h}$ & 0 & 3 & I & 0 & 0 & 0 & 0 & I & 0 & 0 & 0 & 0 \\
\hline
\end{tabular}



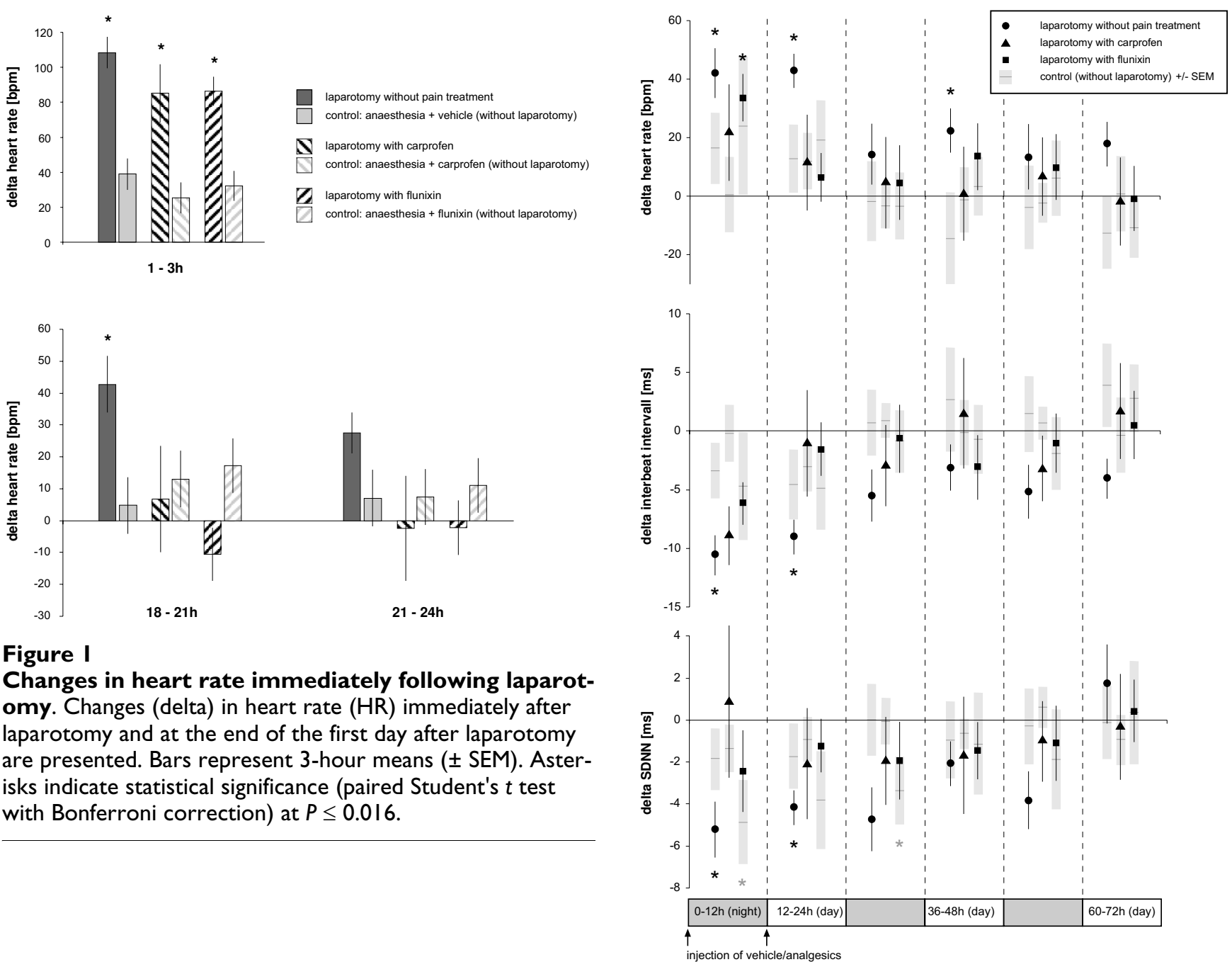

second light phase $(P=0.001$ at $36-48 \mathrm{~h})$. HR was also significantly increased in the first dark phase in the laparotomy group treated with flunixin $(P=0.003$ at $0-12$ h).

A significant decrease in HRV was observed 24 hours after laparotomy without pain treatment, measured both as IBI $(P=0.004$ at $0-12 \mathrm{~h}, P=0.002$ at $12-24 \mathrm{~h})$ and SDNN $(P$ $=0.006$ at $0-12 \mathrm{~h}, P=0.008$ at $12-24 \mathrm{~h})$. SDNN also decreased during the dark phase in the control group that received anaesthesia and flunixin treatment without laparotomy $(P=0.007$ at $0-12 \mathrm{~h}, P=0.002$ at $24-36 \mathrm{~h})$.

ACT and BT after laparotomy and control experiments are reported in Figure 3. No alteration of ACT was found following laparotomy. Only the control group that underwent anesthesia and flunixin treatment showed a decline from $12 \mathrm{~h}$ onwards, with $P$ values ranging from 0.002 to 0.006 . BT increased for $24 \mathrm{~h}$ after laparotomy with carprofen treatment $(P=0.002$ at $0-12 \mathrm{~h}$ and $12-24 \mathrm{~h})$ and from $12-24 \mathrm{~h}$ in the group that was untreated after laparotomy $(P=0.001)$.

Figure 2

Time course analysis of heart rate and heart rate variability following laparotomy. Changes (delta) in heart rate [HR, beats per minute (bpm)], interbeat interval [IBI, milliseconds $(\mathrm{ms})]$, and standard deviation of interbeat interval [SDNN, milliseconds (ms)] relative to baseline (i.e., normal values taken the day before the experiment) are plotted over time. Symbols indicate 12-hour means (bars indicate \pm SEM). Corresponding control experiments in which animals received anesthesia and injections only are depicted as black horizontal lines with grey columns representing \pm SEM.

Asterisks indicate statistical significance $(n=8$, paired Student's $t$ test with Bonferroni correction) at $P \leq 0.008$. Note increased heart rate values with decreased heart rate variability parameters [IBI, SDNN] during the first light phase (I2$24 \mathrm{~h}$ ) in operated animals without pain treatment.

\section{Changes of body weight, food and water intake}

Deviations in body weight, and food and water intake are illustrated in Figure 4. Body weights were significantly reduced for 3 days only in the group with laparotomy 


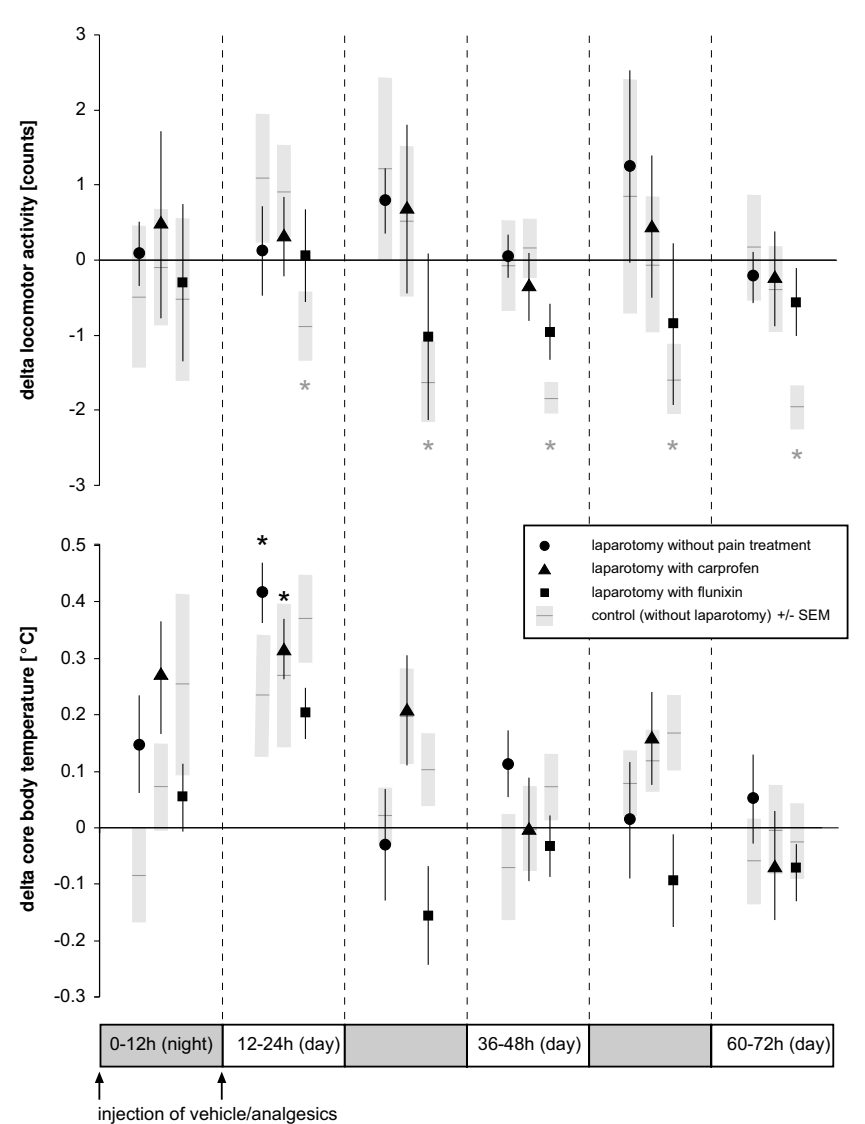

Figure 3

Time course of locomotor activity and core body temperature following laparotomy. Changes (delta) in locomotor activity and core body temperature relative to baseline (i.e., normal values taken the day before the experiment) are plotted against time. Symbols represent I2-hour means (bars indicate \pm SEM). Corresponding control experiments in which animals received anesthesia and injections only are depicted as black horizontal lines with grey columns representing \pm SEM. Asterisks indicate statistical significance ( $n=8$, paired Student's $t$ test with Bonferroni correction) at $P \leq 0.008$.

without pain treatment $(P=0.006$ at day $1, P=0.003$ at day $2, P=0.007$ at day 3$)$. In the same group, food consumption was reduced for two days $(P=0.004$ at day $1, P$ $=0.007$ at day 2). Water intake was decreased in this group, with significance at the second day $(P=0.005)$. Other groups showed increased water consumption after laparotomy and in control experiments, with significance values below 0.009 .

\section{Summary of observations of body condition, behavior and territory}

The criteria used to assess the general condition of the animals are listed in Table 1. A score of 1 could not be assigned to any of the experimental groups as determined

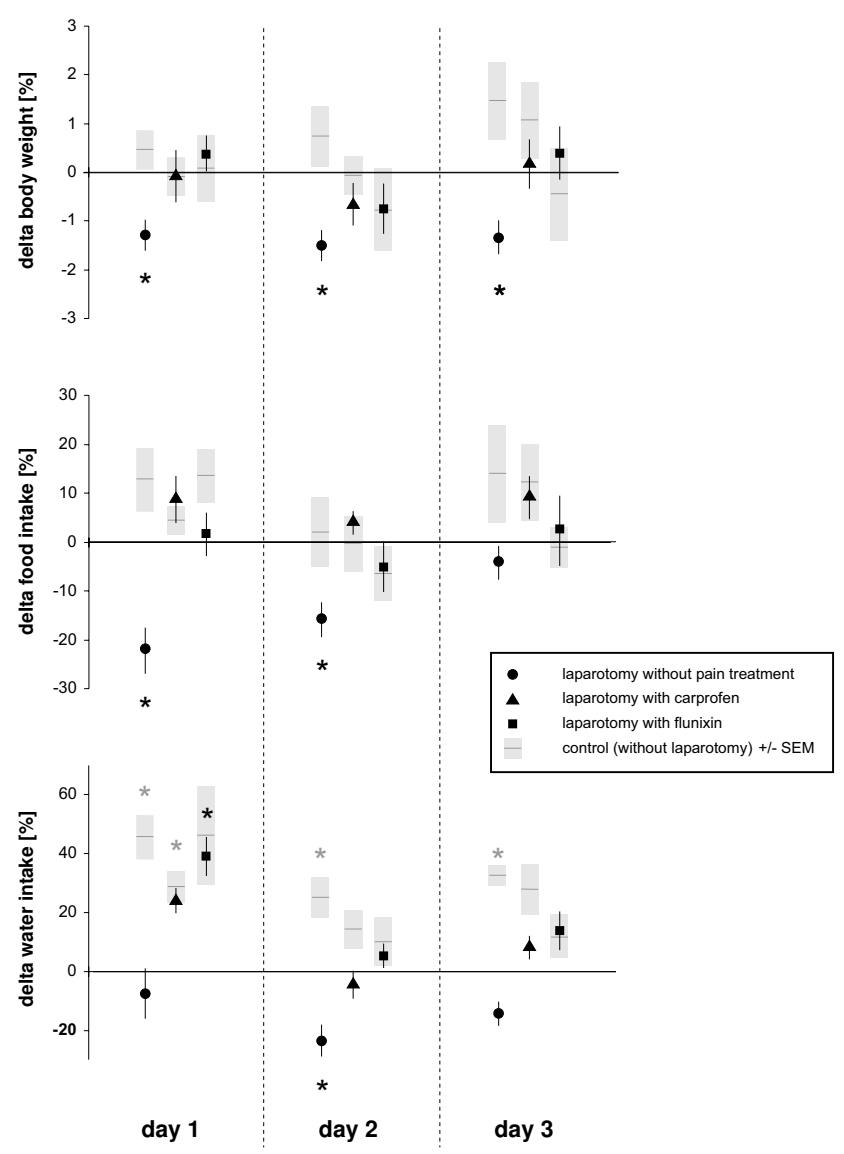

Figure 4

Daily body weight, food and water intake. The percentage deviation (delta) from baseline of body weight, and food and water intake is presented. Symbols represent the mean values from 8 animals, with bars indicating \pm SEM. Corresponding control experiments in which animals received anesthesia and injections only are depicted as black horizontal lines with grey columns representing \pm SEM. Asterisks indicate statistical significance (paired Student's $t$ test with Bonferroni correction) at $P \leq 0.016$. Note the reduction in body weight for three days and the decrease in food consumption for two days after laparotomy without pain treatment.

from observations of the animal's body and general behaviour.

The results from assessment of the appearance of the cage are summarized in Table 2; representative pictures are presented in Figure 5. Unstructured territory, which persisted for 2 days, was detected mainly after laparotomy without pain treatment. Disintegration of the territory was mostly associated with signs of intense digging or the confused distribution of nesting materials in the habitat. In this group, a well-built nest was frequently missing, i.e. either 

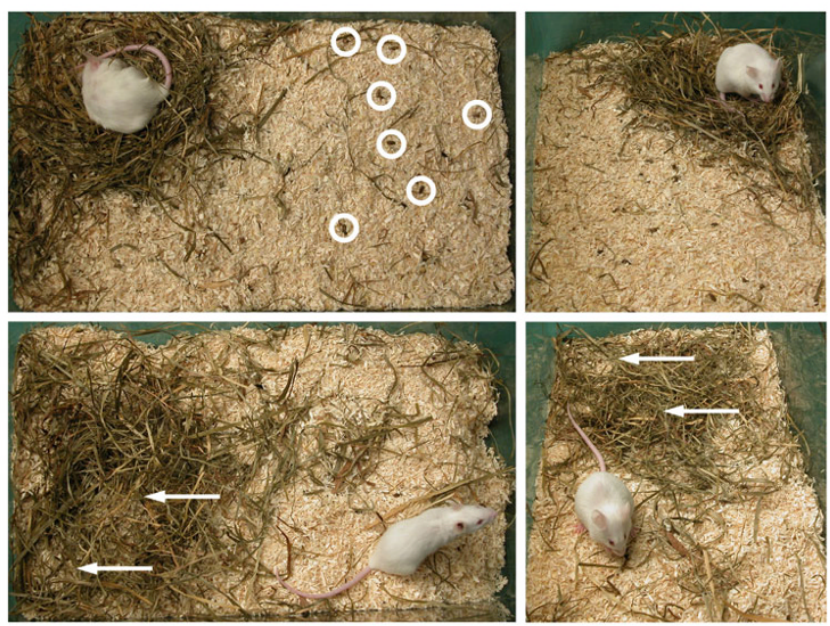

Figure 5

Representative pictures of cage appearance. The upper row indicates Score 0 with a well-built nest and clear structure of the cage area; feces is visible on the beddings surface (circles). The lower row illustrates Score I with an unstructured cage area and two nest-like resting places (arrows).

no nest could be identified or several fragmentary nests at different locations were found during the first day.

\section{Discussion}

In our model, telemetric recordings demonstrated significant alterations in heart action following laparotomy without pain treatment: HR was increased whereas HRV (IBI, SDNN) was decreased for 24 hours. When analgesics were applied, these parameters remained stable at normal, baseline levels, suggesting that the observed alterations in $\mathrm{HR}$ and HRV were associated with pain. This result was corroborated by measurements of body weight and food intake, both of which were significantly reduced if analgesics were omitted after laparotomy. Cage appearance supported an effect of the pain relief regimens; damaged nests and unstructured territory were frequently found in the group in which analgesics were withheld after surgery. Thus, behavioral measures such as food intake and nest building, were in line with aberrant HR and HRV, thus supporting the hypotheses that these parameters can be used as evidence of post-laparotomy pain in our model.

In contrast, no signs of pain could be discriminated by observation and scoring of the animals' bodily condition and spontaneous or provoked moving behaviors. Accordingly, real-time locomotor activity levels were not influenced, confirming that physical exercise was not the cause of the altered HR and HRV measures.
From common knowledge, HR is expected to increase under pain, because autonomous heart actions are adapted by the nervous system to life circumstances such as fear, anxiety, and pain. An increased resting HR compared to healthy controls was described in patients suffering from chronic pain due to irritable bowel syndrome [14] or interstitial cystitis [15]. The short-term response of telemetrically measured HR has been described as a method for studying the analgesic properties of pharmaceutical compounds in an analgesiometric model of visceral pain in rats [16].

In mice, elevated telemetrically measured HR combined with depressed ACT and flattening of circadian rhythms was reported for 5-7 days following implantation of blood pressure transmitters [17]. The magnitude and duration of these alterations, together with the substantial tissue damage from surgery, clearly suggest that this intervention induced a more severe grade of pain than the laparotomy used in our model.

Severe or considerable pain is known to induce apathy, as demonstrated by decreased values of ACT $[18,19]$. We found no aberrations in ACT following laparotomy with or without pain relief. Therefore we conclude that, in our model, animals did not suffer severe pain but rather mildto-moderate pain.

HR measures can be verified by time course analysis of various HRV parameters. One such parameter, the interbeat interval (IBI) detects the distance between R-peaks in the ECG curve, and therefore a decline in IBI confirms elevated HR values. The SDNN is the standard deviation of the IBI in each measuring segment, representing the variability in HR changes. Thus, the SDNN describes the balance between parasympathetic and sympathetic modulation of HR, the decreased values in animals without treatment following laparotomy indicating sympathetic activation $[13,20]$. Similar changes in HR and HRV parameters have been shown to be associated with the progress of laminitis, a disease that is known to cause considerable pain in horses [21].

Although HR and HRV parameters ought to be useful in assessing pain, they have rarely been taken into account because of their sensitivity to various unrelated influences. These additional factors range from experimental interventions, including anaesthesia or medication, to environmental conditions such as an unfamiliar situation (e.g., foreign surroundings, person or companion animal). Whereas pharmaceutical compounds can influence these parameters per se (e.g., by inducing bradycardia), external influences can additionally act on the animal by stimulation of bodily exercise (e.g., running), which naturally leads to an elevation of HR. Such hyperactivity can be 
due to various reasons, one of which, typical for rodents, is novelty. Increased activity is easily evoked by providing animals with a new cage, which is frequently practiced after surgery, but which stimulates mice to explore and occupy the new housing - expressed by physical efforts such as running/walking, digging, climbing and scent marking of the cage area [22]. The influence of a novel cage during the experiment might be an explanation as to why, in another study, evidence of increased HR levels was not provided after laparotomy in mice [23]. In contrast to previous studies, in the present experiments mice were returned to their one-week old cages for recovery following anaesthesia. The inability to identify any significant relationship between nest-damaging behaviour and increased physical exercise as evidenced by the unchanged values of telemetrically recorded ACT levels, suggests that this was not the cause of HR elevation. In addition, the control groups, which received anaesthesia and injections only, displayed minimal rumpling of their nest and cage area, thus supporting our interpretation that this behavior was an expression of discomfort and therefore was related to post-laparotomy pain.

BT was of less importance in our model of laparotomy, where temperatures predominantly increased only in the range of up to $0.5^{\circ} \mathrm{C}$. These moderate changes were also demonstrated in the controls after 12 to $24 \mathrm{~h}$. Although BT measurements were relatively uninformative, they did allow the exclusion of infection (serious inflammation and fever) as an additional factor.

The HR and HRV outcomes were confirmed by the measurements of body weight and food intake, which decreased significantly only if analgesics were omitted after laparotomy. The reduction in food consumption continued for up to 2 days, which is probably the cause for the extended loss of body weight up to 3 days. These symptoms are well-known in animals suffering pain $[3,5,7,19,24-27]$, but they are suggested to be relatively insensitive, or not specific, to pain [6]. From the defined conditions applied in the present study, it is apparent that body weight and food intake are suggestive parameters of pain in our model, but they appear to be both less sensitive and less accurate, especially with regards to determining the duration of pain, compared to HR and HRV.

Water intake proved not to be useful in assessing the wellbeing of the animals. We found an increased demand for fluid after anesthesia, which seemed to be satisfied by increased water consumption. If animals are in pain, water consumption is suggested to be depressed $[2,5,7,9]$, thus fluid homeostasis could be unbalanced if pain is not relieved. Although the curves of water intake supported this assumption, it should be stressed that these data are of limited value due to the fact that artifacts (arising from e.g., accidental loss of water from the bottle) were not taken into account.

Analysis of the descriptive sketches of the cages revealed aberrations only in the group without pain treatment following laparotomy. Many of these animals damaged their nests when they were returned to their home cage after vasectomy. Half of the nests were only properly re-built after more than 2 days and, in some cages, normal structuring of the cage into different areas (i.e., resting places, place for excretion) was not discernable. These aberrations peaked at 12-24 hours, and occurred only rarely in mice that received analgesics and in control mice. We concluded that this nest-destroying behavior was an expression of distress or pain.

The control mice in the experiments served to show whether the observed changes might indicate pharmacologic effects of anesthesia and analgesics that do not reflect pain relief. Control groups that underwent anesthesia and analgesic or vehicle injections without surgery exhibited no substantial effects on the parameters measured. Prolonged effects of anesthesia were excluded by using a short-acting inhalation anesthesia with sevoflurane. As analgesics, two NSAID were chosen, which, to our knowledge, have no relevant effects on the parameters measured here. Whereas no side effects were found with carprofen, flunixin depressed ACT in the control experiment in the long term ( $>12 \mathrm{~h}$ ) and SDNN in night phases. Since the effect of flunixin on the key measures, i.e. HR, IBI, food intake, body weight, nest building and territorial structure after surgery, in the control group was similar to that of carprofen, we concluded that analgesia was the prominent effect, but a sedative side effect could not be completely excluded in the case of flunixin. Concerning the increased HR under flunixin in the first night phase after surgery, we assume that the analgesic effect of flunixin could have been slightly delayed due to subcutaneous application.

In summary, moderate pain was evident for one day after laparotomy without pain relief in our model. Pain was effectively alleviated with carprofen or flunixin $(5 \mathrm{mg} / \mathrm{kg}$ body weight, s.c., bid).

\section{Conclusion}

Surgical intervention as laparotomy induced significant changes of heart rate and heart rate variability parameters (interbeat interval, SDNN) that last for 24 hours. In addition, a significant decrease of food intake during 2 days postoperatively resulted in a significant reduction of body weight for 3 days. Pain therapy with carprofen and flunixin inhibited the changings of heart rate and heart rate variability and maintained food consumption and therefrom body weight remained stable. 
The results show that i.) the method of continuous telemetric monitoring of physiological parameters was able to identify signs of mild to moderate grade pain in mice, which could not be clearly detected otherwise in this species in real-time ii.) analgesic regimens acted successfully in relief of mild to moderate post-operative pain in mice.

In conclusion, heart rate and heart rate variability may be useful in assessing post-operative pain in laboratory mice - provided measurements are recorded continously under standardized conditions in an undisturbed environment. Telemetry was shown to be a useful tool for real-time monitoring of post-operative recovery in mice.

\section{Abbreviations}

Heart rate (HR), electrocardiogram (ECG), core body temperature (BT), locomotor activity (ACT), time domain analysis of heart rate variability (HRV), interbeat interval (IBI), standard deviation of interbeat interval (SDNN).

\section{Authors' contributions}

MA developed the project, conducted the experiments, analyzed the data and drafted the manuscript.

AR and HPK participated in the design of the study, performed statistical analysis and prepared the figures.

PC participated in performing experiments and acquisition and interpretation of data.

KB participated in coordination of the study and helped to draft the manuscript.

All authors read and approved the final manuscript.

\section{Acknowledgements}

We would like to thank the 3R Research Foundation Switzerland and the Foundation for Scientific Research of the University of Zurich for financial support. We also thank Helen Rothnie for helpful suggestions and critical reading of the manuscript.

\section{References}

I. Richardson CA, Flecknell PA: Anaesthesia and post-operative analgesia following experimental surgery in laboratory rodents: are we making progress? Altern Lab Anim 2005, 33:119-127.

2. Baumans V, Brain PF, Brugere H, Clausing P, Jeneskog T, Perretta G: Pain and distress in laboratory rodents and lagomorphs. $L a b$ Anim 1994, 28:97-II2

3. Hawkins P: Recognizing and assessing pain, suffering and distress in laboratory animals: a survey of current practice in the UK with recommendations. Lab Anim 2002, 36:378-395.

4. Baumans V: Methods for evaluation of laboratory animal wellbeing. Altern Lab Anim 2004, 32:161-162.

5. van Sluyters RC, Obernier A: Guidelines for the care and use of mammals in neuroscience and behavioral research. Contemp Top Lab Anim Sci 2004, 43:48-52.

6. Peterson NC: Assessment of pain scoring. Contemp Top Lab Anim Sci 2004, 43:74.
7. Stasiak KL, Maul D, French E, Hellyer PW, VandeWoude S: Speciesspecific assessment of pain in laboratory animals. Contemp Top Lab Anim Sci 2003, 42: 13-20.

8. Tang $X$, Yang $L$, Sanford LD: Sleep and EEG spectra in rats recorded via telemetry during surgical recovery. SLEEP 2007, 30: in press..

9. Morton DB, Griffiths PH: Guidelines on the recognition of pain, distress and discomfort in experimental animals and an hypothesis for assessment. Vet Rec 1985, I | 6:43 I-436.

10. Nicklas W, Baneux P, Boot R, Decelle T, Deeny AA, Fumanelli M, IIIgen-Wilcke $B$ : Recommendations for the health monitoring of rodent and rabbit colonies in breeding and experimental units. Lab Anim 2002, 36:20-42.

II. Spani D, Arras M, Konig B, Rulicke T: Higher heart rate of laboratory mice housed individually vs in pairs. Lab Anim 2003, 37:54-62.

12. Gehrmann J, Hammer PE, Maguire CT, Wakimoto H, Triedman JK, Berul Cl: Phenotypic screening for heart rate variability in the mouse. Am J Physiol Heart Circ Physiol 2000, 279:H733-40.

13. Malik M: Heart rate variability: standards of measurement, physiological interpretation and clinical use. Task Force of the European Society of Cardiology and the North American Society of Pacing and Electrophysiology. Circulation 1996, 93:1043-1065.

14. Gupta V, Sheffield D, Verne GN: Evidence for autonomic dysregulation in the irritable bowel syndrome. Dig Dis Sci 2002, 47: $1716-1722$.

15. Lutgendorf SK, Latini JM, Rothrock N, Zimmerman MB, Kreder KJ Jr.: Autonomic response to stress in interstitial cystitis. J Urol 2004, I 72:227-23।.

16. Nijsen MJ, Ongenae NG, Coulie B, Meulemans AL: Telemetric animal model to evaluate visceral pain in the freely moving rat. Pain 2003, 105: I I5-I23.

17. Butz GM, Davisson RL: Long-term telemetric measurement of cardiovascular parameters in awake mice: a physiological genomics tool. Physiol Genomics 2001, 5:89-97.

18. Clement JG, Mills P, Brockway B: Use of telemetry to record body temperature and activity in mice. J Pharmacol Methods |989, 2 | : |29-|40.

19. Hayes KE, Raucci JA Jr., Gades NM, Toth LA: An evaluation of analgesic regimens for abdominal surgery in mice. Contemp Top Lab Anim Sci 2000, 39: I8-23.

20. Sgoifo A, Koolhaas J, De Boer S, Musso E, Stilli D, Buwalda B, Meerlo $P$ : Social stress, autonomic neural activation, and cardiac activity in rats. Neurosci Biobehav Rev 1999, 23:915-923.

21. Rietmann TR, Stauffacher M, Bernasconi P, Auer JA, Weishaupt MA: The association between heart rate, heart rate variability, endocrine and behavioural pain measures in horses suffering from laminitis. J Vet Med A Physiol Pathol Clin Med 2004, 5 I :2 I 8-225.

22. Kramer K, van Acker SA, Voss HP, Grimbergen JA, van der Vijgh WJ, Bast A: Use of telemetry to record electrocardiogram and heart rate in freely moving mice. J Pharmacol Toxicol Methods 1993, 30:209-215.

23. Goecke JC, Awad H, Lawson JC, Boivin GP: Evaluating postoperative analgesics in mice using telemetry. Comp Med 2005, 55:37-44.

24. van Loo PLP, Everse LA, Bernsen MR, Bauman V, Hellebrekers LJ, Kruitwagen $C L J$ J, den Otter W: Analgesic in mice used in cancer research: reduction of discomfort. Lab Anim 1997, 3 I:3 I8-325.

25. Peterson NC: Behavioral, clinical, and physiologic analysis of mice used for ascites monoclonal antibody production. Comp Med 2000, 50:516-526.

26. Aldred AJ Cha, M. C., Meckling-Gill, K. A.: Determination of a humane endpoint in the LI2 10 model of murine leukemia. Contemp Top Lab Anim Sci 2002, 41:24-27.

27. Clark MD, Krugner-Higby L, Smith LJ, Heath TD, Clark KL, Olson D: Evaluation of liposome-encapsulated oxymorphone hydrochloride in mice after splenectomy. Comp Med 2004, 54:558-563. 